residual radioactivity in serum after incubation with resin is assessed and therefore a free thyroxine index is caloulated as described by Dr. D'Haene and his colleagues by dividing P.B.I. by T-3 B.C. index.

We hope this comment clarifies the situation and reinforces the need for a clear understanding of the method used to assess the $\mathrm{T}-3$ resin uptake.-We are, etc.,

Department of Medicine

F. Clark

University of Newcastle upon Tyne

D. B. HORN

Department of Clinical Chemistry,

Western General Hospital,
Edinburgh

1 Clark, F., and Horn, D. B., fournal of Clinical Endocrinology, 1965, 25, 39.

2 Clark, F., and Brown, H. J., British Medical

Fournal, 1970, 2, 543 and 672. Clark, F., and Brown, H. J., British Medical
fourmal, 1970, 1, 713.

SIR,-Dr. E. G. M. D'Haene and others (21 September, p. 708) have compared the free thyroxine index (F.T.I.) and effective thyroxine ratio (E.T.R.) using correlation coefficients (Sipearman rank correlation) and a minimum of experimental evidence. We fesl that a number of points and the final conclusions may mislead potential users of one-tube free thyroxine tests.

(1) The correlation coefficient, however derived, between F.T.I. and E.T.R. does not reflect the ability of these tests to sort out the patients into the three categories, hypohyper-, and euthyroid. Thus the fact that there is no significant correlation between F.T.I. and E.T.R. values falling inside the normal range is not relevant in any way to the final diagnosis.

(2) While the use of comparison of "objective measurements" with "subjective clinical impressions" is certainly dangerous and difficult in practice, it is nevertheless essential for tests to be judged at some stage by their practical usefulness. Thus the observations of Thorson et al.,1 Murray et al., and ourselves (in an unpublished retrospective survey) that the diagnostic accuracy of the E.T.R. was in practice about $99 \%$, $94.5 \%$, and $94 \%$ retrospectively àre more relevant than the judgement of a test by its correlation with another, different, "objective measurement."

(3) The statement that "correction for binding-protein abnormalities ... when the free $T-4$ index is calculated, is more trustworthy than the chemically regulated correction which is more or less automatically and uncontrollably applied when measuring the E.T.R." (our italics) is based on a claim that at high conoentrations of thyroxine $(\mathrm{T}-4)$ a greater percentage of labelled $\mathrm{T}-4$ binds to the thyroxine - binding proteins than is found if triiodothyronine (T-3) is used instead. A reduction of the $\mathrm{T}-4$ concentration results in binding "more or less identical" with that of T-3. They appear to have overlooked two points: (a) The non-labelled $\mathrm{T}-4$ acts similarly to labelled $T-4$ and so their addition of $0.5 \mathrm{~m}$ normal serum to each 3-ml phial (instead of $0.5 \mathrm{ml} / 100 \mathrm{ml}$ in the E.T.R.) will increase the final concentration of $\mathrm{T}-4$ from 1.03 to about $15.8 \mathrm{nmol} / \mathrm{l}$. Even after their reduction of labelled $T-4$ to $0.21 \mathrm{nmol} / \mathrm{l}$. their total concentration is about $14.9 \mathrm{nmol} / 1$. while the E.T.R. normally contains about $3.5 \mathrm{nmol} T-4 / 1$. (b) The equivalent concen- tration of $T-3$ used in the experiments is about one-fifth that of $\mathrm{T}-4$ and so their comparisons between the binding of these substances to thyroxine-binding globulin were not valid.

Dr. D'Haene and his colleagues conclude that "at present there are no convincing reasons" for using E.T.R. instead of F.T.I. The time required to carry out both $T-3$ resin uptake and total $\mathrm{T}-4$ estimation and their cost are about double those of singletube tests such as E.T.R. It would seem to us that a reduction in cost and time of rained personnel would be sufficient reasons for preferring a single test procedure of comparable diagnostic reliability. Add to this a smaller coefficient of variation (even found by Dr. D'Haene and his colleagues) and a proved value for both diagnosis and monitoring treatment and it would need a convincing reason indeed to use F.T.I. instead of E.T.R. as an index of thyroid function.-We are, etc.,

M. G. WELLS

Radioche nistry Department,

C. E. ANDREW

(a)

Thorson, S. C., et al., British Medical fournal, Murray, I. P. C., et al., British Medical fournal, $1972,1,1190$.

\section{TSH Level and Thyroid Function}

SIR,-Dr. G. Antony in his letter (14 September, p. 688) commenting on our paper (13 July, p. 89) has expressed the opinion that patients with normal levels of circulating thyroid hormones and raised serum thyroid-stimulating hormone (TSH) levels should be described as having subclinical or compensated hypothyroidism. He thus prefers to emphasize the presence of an abnormality in the thyroid-pituitary axis rather than that the effects of this abnormality are not clinically recognizable. $\mathrm{He}$ goes on to say that the choice of a particular diagnostic term tends to determine the management of the patient, which might be taken to imply that these patients should be treated with thyroxine. We think such a policy is mistaken. As long as no therapeutic implication is attached to any of these terms, they may be regarded as interchangeable. The patients in auestion were clinically euthyroid (whichever term is used to describe their condition) and may remain so for many years. In our opinion the prognostic significance of an elevated TSH level in these patients remains to be established and we consider that therapy should be introduced only when there is evidence of inadequate ciroulating thyroid hormone levels and symptoms or signs of hypothyroidism.

Part of the difficulty in this situation is that none of the terms are entirely satisfactory from a clinical, biochemical, and physiological point of view. We agree that there is a need to look for ways of measuring the peripheral effects of TSH and thyroid-releasing hormone (TRH) as well as the peripheral effects of the circulating thyroid hormones. Until it is established that a sustained elevation of TSH in the presence of normal levels of ciroulating thyroid hormones has an adverse effect we feel that our understanding of the condition of such patients is better served by careful follow-up. We prefer to emphasize the clinical status of the patient, as we feel that this should govern our approach to therapy. It may occasionally be difficult to assess whether circulating levels of thyroid hormones are inadequate, as for instance in patients who have subnormal levels of serum thyroxine ( $\mathrm{T}-4)$ but normal levels of serum triiodothyronine (T-3). We do not, however, consider therapeutic intervention justified in patients who have normal serum levels of both $\mathrm{T}-4$ and $\mathrm{T}-3$. - We are, etc.,

W. M. G. TUNBRIDGE

Royal Victoria Infirmary Newcastle upon Tyne

P. HARSOULIS

Hammersmith Hospital A. W. G. GOOLDEN London $W .12$

\section{Dangers of Oxytocin-induced Labour to Fetuses}

SIR,-I should like to congratulate $\mathrm{Mr}$. W. A. Liston and Mr. A. J. Campbell (7 September, p. 606) for reminding us of the perinatal hazards that may be associated with oxytocin stimulation of labour. Indeed, in clinical practice poor patient selection and faulty methodology all too often confirm the validity of their conclusions. However, when the indication for using an oxytocic is correct and when hyperstimulation is avoided, the procedure per se does not cause fetal distress in the first stage of labour. This holds true for both oxytocin and prostaglandins. ${ }^{12}$ On the other hand abnormal fetal heart rate patterns may appear without warning during the second stage of labour, pointing to fetal distress and making prompt delivery imperative. ${ }^{3}$ Both uterine hyperstimulation and pathological fetal heart rate patterns are most aocurately diagnosed by electronic monitoring of labour and I feel, as do Mr. Liston and Mr. Campbell, that this should form an integral part of any induction trial.-I am, etc.,

Department of Obstetrics, State University of Ghent,

M. THIERY Belgium

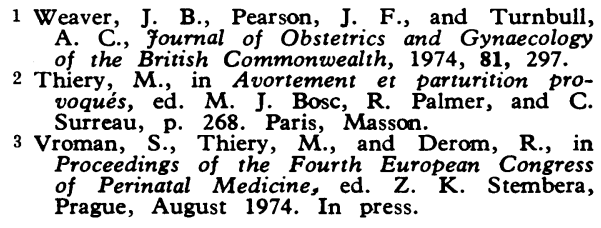

\section{Diet and Coronary Heart Disease}

SIR,-The main burden of the letter of Drs. K. P. Ball and R. W. D. Turner (21 September, p. 740) appears to be that the dietary recommendations of the Committee on Medical Aspects of Food Policy ${ }^{1}$ are perverse in that they differ from those of many other committees from several other countries. Certainly this committee's report could have been produced in a much shorter time than the three years it did take, and would have required far fewer drafts than the 10 it did produce, if all it had to do was to count the views expressed in earlier reports. What it did do was to look afresh at the evidence that existed and use its own judgement in deciding how far it pointed 
to likely ways in which heart disease could be prevented by alteration in diet.

Drs. Ball and Turner give the impression, too, that there is a fairly broad consensus in the dietary recommendations. This is just not true. Some authorities but not all recommend a reduction in cholesterol; some but not all a reduction in dietary fat; some but not all an increase in polyunsaturated fat; some but not all a reduction in saturated fat. Even within the reports there are sometimes impor:ant differences in the opinions expressed by individual members of the committees producing them.

The truth is that very experienced and respected research workers continue sinoerely to hold different and even contradictory views. Any statement that suggests otherwise, whether from those in the health profession or from the food industry, is unwarranted and misleading.-I am, etc.,

Servier Research Institute,

JOHN YUDKIN

Greenford, Middlesex

1 Department of Health and Social Security, Diet Subjects 7. London, H.M.S.O., 1974.

SIR,-May I refer to the letter from Drs. K. P. Ball and R. W. D. Turner (21 September, p. 740)?

Since $1956,1^{12}$ and more particularly in a recently published work, ${ }^{3}$ I have related coronary disease to the consumption of the refined carbohydrates, including such examples as white flour and even beer, all of which can raise the blood glucose to higher levels than would occur with natural, unrefined carbohydrates. ${ }^{4}$ If this is done the association of coronary disease with obesity, and especially with diabetes, falls into plaoe naturally and the whole subject becomes greatly simplified; whereas relating the disease only to the consumption of table sugar (sucrose) fails, just as it fails in the case of obesity, and for that matter diabetes. ${ }^{5}$

Drs. Ball and Turner would like us to consume much less animal fats, which (including milk fats) are of very ancient lineage, dating not only from biblical times ${ }^{6}$ but also from neolithic times even more remote; and they would like us to eat, instead, much more polyunsaturated fats such as are present in sunflower seed and other vegetable oils, most of which were never seen as such on this planet until the invention of the hydraulic press and the new solvent procedures. This evolutionary incongruity presents a perpetual challenge to the logic of any substitution in fats on the above lines. No grass-feeding or other type of feeding in animals, as I try to show in my work, removes this incongruity either.

But quite apart from this, the present coronary explosion has not been preceded by any marked increase in fat consumption, least of all as regards animal fats, whereas it has been preceded by an enormous increase in sugar consumption, all of which I have also tried to show from many sources.

Dr. Samuel Johnson, in a well known passage, said that nothing concentrated a man's thoughts so much as the knowledge that he is going to be hanged in the morning. The incidence of coronary disease in westernized countries is now of epidemic proportions, accounting in these islands for a quarter of all deaths, and, alas, our own profession is affected about as much as any other. It is therefore desirable for each one of us to concentrate his thoughts on the possible causative factors and use his own judgement thereon. For our lives are at stake on the decision. And I submit that the more closely we adhere to natural (=evolutionary) principles and the less we try to be clever at nature's expense, the safer we shall be.- I am, etc.,

Catisfield,

T. L. Cleave Fareham, Hants

1 Cleave, T. L., Fournal of the Royal Naval Medical Service, 1956, $42,4$. Cleave, T. L., Fat Consumption and Coronary
Disease. Bristol, Wright, 1957 .

3 Cleave, T. L., The Saccharine Disease. Bristol,

Wapnick, S., et al., Lancet, 1972, 2, 300

5 Cleave, T. L., Lancet, 1971, 1, 43.

6 Deuteronomy, xxxii, 14.

\section{Consistent Chromosome Abnormalities in} Acute Leukaemia

SIR,-Chromosomes of patients suffering from acute leukaemia have been studied in many different laboratories ${ }^{12}$ but no consistent abnormality has been found. Clonal cytogenetic abnormalities have been detected in only $30.4 \%$ of our patients, ${ }^{3}$ and though particular abnormalities were characteristic of each patient in relapse in no case was there a correlation between the type of abnormality and the type of disease or with the length of the remission period. Cells of patients in remission always appeared to have a normal 46 chromosome complement.

Recently we have examined bone marrow samples by an adaptation of Seabright's trypsin/Giemsa banding technique ${ }^{4}$ and have obtained more critical data. The chromosomes of three patients (A.M., T.K. I.W.) with acute myeloblastic leukaemia have been examined by this technique and the results are shown in fig. 1 and in the table. Cells of patients A.M. and T.K. were examined while they were in haematological remission and had been treated with cytotoxic drugs for two and 12 months respec tively. The cells of I.W. were examined in his initial haematological relapse before any drugs had been administered. With banding techniques all three patients exhibited

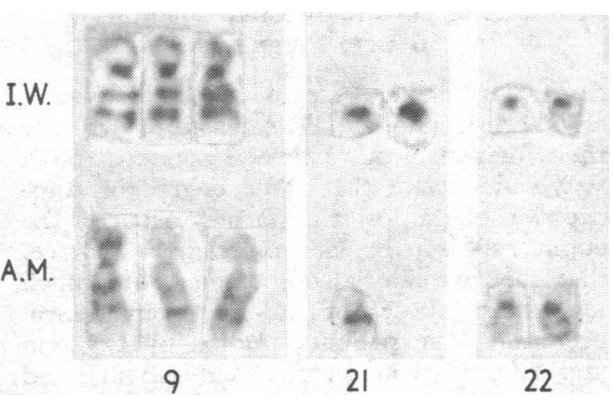

FIG. 1.-Banded chromosomes from patients I.W. and A.M.

Karyotypes of Cells derived from Bone Marrow or Peripheral Blood in Three Patients with Acute Myeloblastic Leukaemia

\begin{tabular}{|c|c|c|c|c|}
\hline Patient & Diagnosis & Condition & Karyotype (Sample) & \\
\hline $\begin{array}{l}\text { A.M. } \\
\text { T.K. } \\
\text { I.W. }\end{array}$ & $\begin{array}{l}\text { A.M.M.L. } \\
\text { A.M.L. } \\
\text { A.M.L. }\end{array}$ & $\begin{array}{l}\text { Remission } \\
2 \text { months } \\
\text { Remission } \\
12 \text { months } \\
\text { Relapse } \\
\text { (pretreatment) }\end{array}$ & $\begin{array}{l}* 45, X Y,-8,+9,-21 \\
46, X Y \\
* 46, X Y,-8,+9 \text {,dup ?(21)(q21) } \\
46, X Y \\
46, X Y(P / B \text { with PHA) } \\
45, X Y,-4,+9 \text {,dup ?(21)(q21) } \\
100 \% \text { ? }\end{array}$ & $\begin{array}{l}\mathbf{B} / \mathbf{M} \\
\mathbf{B} / \mathbf{M} \\
\mathbf{B} / \mathbf{M}\end{array}$ \\
\hline
\end{tabular}

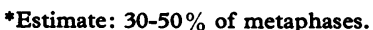

similar cytological pictures-trisomy 9 was apparent and one member of the chromosome 21 pair was missing or altered in all three patients. One chromosome 8 was missing in A.M. and T.K. Since I.W. showed similar abnormalities to A.M. and T.K. these abnormalities had not been induced by cytotoxic drugs.

Our observations are interesting for two main reasons-firstly, because they indicate that acute leukaemias do manifest consistent cytogenetic pictures and, secondly, because they show that patients in haematological remission can still retain cytogenetically aberrant cells. They thus suggest that acute leukaemia is not "cured" when the patient is in haematological remission but that, as in chronic granulocytic leukaemia, the disease still persists.

In one patient with acute myeloblastic leukaemia Jonasson et al. ${ }^{5}$ demonstrated a clone of cells which were $47+8$ and pointed out that such $47+8$ clones have also been found in sideroblastic anaemia, a condition often considered to be preleukaemic. We have not found any +8 clones in our material, and yet such clones might be generated if a $46-8+9$ cell was formed by non-disjunction (fig. 2). In their study of an adult patient with myelomonoblastic leukaemia Rutten et al. ${ }^{6}$ observed a clone of cells which were $47+9$. Neither of these authors, however, studied cells with only 46 ohromosomes by banding.

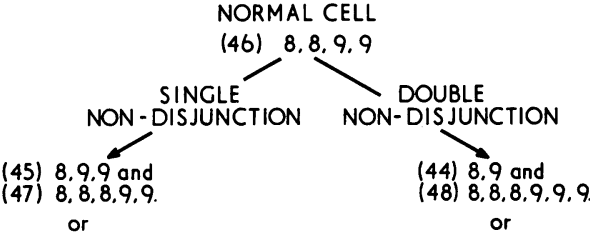

(45) $8,8,9$ and

(46) $8,8,8,9$ and

(47) $8,8,9,9,9$

(46) $8,9,9,9$

FIG. 2.-Abnormal ratios of number 8 and 9 hromosomes derivable by single or double nondisjunction events. suggest at this stage that the important cytogenetic picture may be one of an imbalance between the number 8 and number 9 chromosomes in the leukaemic cell, and it is interesting that the number 9 chromosome has also been implicated in chronic myeloid leukaemia. ${ }^{7}$ It may also be significant that chromosome 21 appears to be involved in acute leukaemia and also in Down's synincreased incidence of leukaemia.-We are, etc.,

JUDITH H. FORD Sally M. PitTMan FREDERICK W. GUNZ

Kanematsu Memorial Institute, Sydney Hospital,
Our results and the others mentioned drome (trisomy 21), which shows a much 